\title{
IDIOPATHIC HYPERKINETIC STATE: A NEW CLINICAL SYNDROME
}

\author{
BY \\ NORMAN BRACHFELD AND RICHARD GORLIN* \\ From the Medical Clinics, Peter Bent Brigham Hospital and Department of Medicine, \\ Harvard Medical School, Boston, Mass., U.S.A. \\ Received September 1, 1959
}

A number of new or hitherto inadequately defined diseases of the heart have been described in recent years. Among these have been subendocardial fibrosis (Thomas et al., 1954), localized outflow tract hypertrophy (Brock, 1957), and viral myocardiopathy (Silber, 1958) as causes of heart failure, and rheumatoid spondylitis (Clark and Bauer, 1948), Marfan's syndrome (McKusick, 1955), and the carcinoid syndrome (Mattingly and Sjoerdsma, 1956) as precursors of valvular disease. In addition, the introduction of accurate diagnostic techniques has indicated that a certain percentage of so-called functional heart murmurs are related to definite, although mild, anatomical cardiac defects (unpublished data).

In the past three years, we have had the opportunity to study and observe a group of eight patients who have in common certain clinical and physiological abnormalities described in the following case histories. We believe they comprise a hitherto undescribed form of heart disease, possibly related to chronic elevation of the cardiac output.

\section{CASE REPORTS}

Case $1(G . S$.). This patient was an 18-year-old college freshman referred for study because of a murmur heard on routine examination. He had participated actively in school athletics. A mild rise of systolic blood pressure had been observed during various school physical examinations. There was no history of scarlet fever or rheumatic fever. His father had mild hypertension; his mother was said to be unusually "nervous."

Physical Examination. Blood pressure 145/73; heart rate 94. The patient was well developed, well nourished and appeared normal. Except for a slightly increased carotid pulse, arterial pulsation was normal. The jugular venous pressure was normal. There was no cardiac enlargement. The apical impulse and heart sounds were normal. A grade 2+, short mid-systolic murmur was heard along the left sternal border and at the base, and increased with effort. The electrocardiogram revealed left ventricular hypertrophy, increased Q-T interval, and slightly elevated S-T segment with high T wave in V4 to V6 attributed to diastolic overloading of the left ventricle (Sodi-Pallares and Calder, 1956). The pulmonary vascular markings in the X-ray were slightly increased.

Special Studies. Right heart catheterization revealed normal pulmonary pressures at rest and during exercise. Blood oxygen samples gave no evidence for left-to-right shunt. Fick cardiac outputs measured at rest and five minutes following cessation of exercise were abnormally raised $\left(5.81 . / \mathrm{min} . / \mathrm{m} .{ }^{2}\right)$. The cardiac output was not much different during effort. Oxygen consumptions were $197 \mathrm{ml} . / \mathrm{min} . / \mathrm{m} .^{2}$ at rest and doubled after four minutes of exercise. Arteriovenous oxygen differences were narrowed at rest but widened normally following exercise. Blood pressure increased from 145/73 at rest to 170/90 on effort.

One week later, studies performed following administration of $90 \mathrm{mg}$. of phenobarbitone again demonstrated abnormally increased cardiac outputs $\left(5 \cdot 3,4 \cdot 7\right.$, and $6 \cdot 11 . / \mathrm{min} . / \mathrm{m} .{ }^{2}$ (method of Pritchard et al., 1958)). Two months later, an output of $5 \cdot 31 . / \mathrm{min} . / \mathrm{m} .{ }^{2}$ decreased 40 per cent during sleep. Thyroid studies including protein-bound iodine, urinalysis, complete blood count, blood urea nitrogen, fasting blood sugar,

* Investigator, Howard Hughes Medical Institute. This work was supported by grants from the United States Public Health Service (N.I.H. H-2637), the Kriendler Memorial Foundation, Wyeth Laboratories, Massachusetts Heart Association (\#390) and Warner-Chilcott Laboratories. 
lactates, pyruvates, catechol amines, blood volumes, and hematocrit were within normal limits. A cold pressor test was strongly positive.

Course. Persistent abnormalities were detected over a one-year period. Serpasil, $0 \cdot 25 \mathrm{mg}$. daily, was then begun. At the end of one month of therapy, cardiac output at rest was $2 \cdot 91 . / \mathrm{min} . / \mathrm{m} .^{2}$ and blood pressure $125 / 70$ with a normal rise in both on effort.

Comment. The systolic hypertension seemed to correlate well with the high stroke volume recorded on three separate occasions with and without sedation.

Case 2 (R. L.). The patient, a 22-year-old male barber, had been in good health and had had normal effort tolerance throughout his life. A murmur was apparently heard at the age of three, but there was no history of rheumatic fever or scarlet fever. No heart disease was known in the family.

Physical Examination. The patient showed a moderate pectus excavatum and a mild kyphosis, but he was otherwise well developed and well nourished. The blood pressure was 150/75 and the pulse 95 . The heart was normal in size, but with a forceful and diffuse apical impulse. There was a grade 3, pan-systolic murmur heard over the right præcordium, but loudest in the third left intercostal space. The electrocardiogram showed incomplete right bundle-branch block and the chest X-ray was normal.

Special Studies. Right heart catheterization revealed a Fick cardiac output of $6 \cdot 81 . / \mathrm{min} . / \mathrm{m} .{ }^{2}$, normal pulmonary pressures, and no evidence of a left-to-right shunt. Arterial oxygen saturation was normal $(97 \%)$. The $\mathrm{O}_{2}$ consumption at rest was $171 \mathrm{ml} . / \mathrm{min} . / \mathrm{m}^{2}$ and was more than doubled during effort. Similar hæmodynamic findings were obtained one year later. Laboratory studies including protein-bound iodine were negative. A cold pressor test was strongly positive.

Comment. The mild degree of pectus deformity which did not displace the heart was not thought to be responsible for the abnormal physiological and clinical findings which persisted during a one-year period of observation.

Case 3 (L.P.). The patient, a student aged 17, had been entirely asymptomatic and very active in sports. There was no history of rheumatic fever or scarlet fever and no family history of heart disease. A murmur was first noted on examination for military service.

Physical Examination. He was thin, but otherwise well developed and well nourished. The blood pressure was 125/75 and the pulse 80 . The carotid pulses on each side were full. The jugular venous pressure was normal. The heart was normal in size on percussion, but there was an increased left ventricular tap. The first sound at the mitral area was slightly increased. P2 was louder than A2 and split. There was a grade 2, early soft systolic murmur, loudest at the lower left sternal border and radiating to the apex and base. The remainder of the examination was negative. The electrocardiogram denoted left ventricular hypertrophy and sinus arrhythmia, while the X-ray showed normal appearances of the heart and lungs.

Special Studies. Right heart catheterization showed normal pulmonary and systemic pressures and no evidence of a left-to-right shunt. Cardiac outputs, determined at separate times by both the Fick and dye dilution methods, were raised $\left(5.31 . / \mathrm{min} . / \mathrm{m} .{ }^{2}\right.$ and $6.01 . / \mathrm{min} . / \mathrm{m}^{2}$ respectively). Oxygen consumption was normal $\left(162 \mathrm{ml} . / \mathrm{min} . / \mathrm{m}^{2}\right)$ and the arteriovenous oxygen difference was narrowed $(2 \cdot 7$ vol. per cent). Pertinent laboratory studies (see Case 1 for detailed list) were within normal limits.

Case $4(R . A$.). The patient was a 35-year-old labourer, who was referred for cardiac evaluation because of a murmur known to be present for 15 years. He had not had scarlet fever or rheumatic fever, and no heart disease was known in his family. The patient had stuttered from early youth and was "nervous" as far back as he could remember. He had complained occasionally of diffuse præcordial distress with emotional upsets, but not with exercise.

Physical Examination. The patient was anxious-looking, well developed, and well nourished. Blood pressure 110/65; pulse 80 . The carotid pulsations were increased in amplitude and the jugular venous pressure was normal. The heart was not enlarged, but the left ventricular impulse was slightly increased. The heart sounds were normal but there was a grade 3, basal systolic murmur which was not transmitted to the neck. The electrocardiogram revealed left ventricular hypertrophy and the chest X-ray was normal except for moderate pulmonary plethora.

Special Studies. Right heart catheterization revealed normal pulmonary pressures and no evidence for a left-to-right shunt. Oxygen consumption was $158 \mathrm{ml} . / \mathrm{min} . / \mathrm{m} .{ }^{2}$ at rest and doubled on exercise. Cardiac outputs, measured by the Fick and isotope methods (Pritchard et al., 1958) during catheterization, averaged $5 \cdot 71 . / \mathrm{min} . / \mathrm{m}^{2}$ at rest. Eight months later, the cardiac output was $4 \cdot 71 . / \mathrm{min} . / \mathrm{m} .{ }^{2}$ and did not change during sleep. A cold pressor test was strongly positive. Pertinent laboratory tests (see Case 1 for detailed list) were all within normal limits.

Comment. The præcordial chest pain spontaneously disappeared and has not returned. Abnormalities were observed and documented over a period of one and a half years prior to this report. 
Case 5 (R. R.). This patient was an 18-year-old male student referred for evaluation of a cardiac murmur. At the age of four he was found on X-ray to have an enlarged heart but apparently no murmur was heard. He grew and developed normally and never had rheumatic or scarlet fever or any serious illness. He was a vigorous athlete and a member of a football team when first seen. Four months before he came under observation, during an attack of influenza, his medical attendant heard a grade 1 "functional" murmur. Because of "pleurisy" and malaise, an electrocardiogram was taken. This showed high voltage, delayed intrinsicoid deflection and upright $T$ waves over the left præcordium. Recovery from this illness was rapid and complete. The murmur and abnormal electrocardiogram were again noticed several months later during a routine medical examination. The family history was normal except for a brother with sinus bradycardia.

Physical Examination. Blood pressure 120/70; pulse 74. The patient looked anxious but in good health. Carotid arterial pulsations were somewhat increased. The heart was normal in size, rhythm, and force of impulse. The mitral first sound was slightly increased; P2 was normal. There was a grade 2, systolic murmur, loudest along the left sternal border, heard also at the apex, and increased with effort. The electrocardiogram showed left ventricular hypertrophy. The pulmonary arterial markings were increased and the left ventricle prominent in the X-ray.

Special Studies. The cardiac output determined two months before right heart catheterization was $8.31 . / \mathrm{min} . / \mathrm{m} .{ }^{2}$ with little change on exercise. Right heart catheterization revealed normal pulmonary pressures and no evidence of a left-to-right shunt. Arterial oxygen saturation was 99 per cent. Despite sedation, the arteriovenous oxygen difference was narrow $(2 \cdot 7$ vol. per cent) and cardiac output averaged $7 \cdot 81 . / \mathrm{min} . / \mathrm{m} .{ }^{2}$. Brachial artery pressure recorded on four separate occasions showed pressures between 140 and $180 \mathrm{~mm}$. systolic and 75 to $90 \mathrm{~mm}$. diastolic. Heart rate at rest varied from 72 to 90 . Further determinations 14 months after right heart catheterization revealed an output of $6.71 . / \mathrm{min} . / \mathrm{m} .{ }^{2}$ which did not change during the dozing state. Ancillary laboratory studies (see Case 1 for detailed list) were normal. A cold pressor test was negative.

Comment. Circulatory and electrocardiographic abnormalities were found over a two-year period of observation. Following one month of serpasil, $0.25 \mathrm{mg}$. daily, resting cardiac output was found to be normal $\left(3 \cdot 61 . / \mathrm{min} . / \mathrm{m} .^{2}\right)$ with a blood pressure of $125 / 70$.

Case $6(B . H$.$) . The patient was a 48-year-old man with a reported valve lesion since the age of 6$ and rheumatic fever at the age of 25. Symptoms of pulmonary and peripheral congestion with œdema had developed 12 years before admission, and had been controlled with therapy. Symptoms recurred and he was admitted for study.

Physical Examination. He was thin with engorged and pulsating neck veins and prominent carotid arterial pulsation. The blood pressure was 124/60; auricular fibrillation at the rate of 105 a minute. Râles were heard at the lung bases. The heart was enlarged to the anterior axillary line with both right and left ventricular heaves. There was a grade 4 præcordial systolic and a grade 4 apical mid-diastolic murmur. The liver edge was felt two finger breadths below the right costal margin, and pretibial odema extended up the shin. The electrocardiogram showed right ventricular hypertrophy and auricular fibrillation. On X-ray the heart was increased in transverse diameter 58 per cent above normal; there was notable dilatation of the pulmonary artery and right ventricle, and slight dilatation of the left atrium.

Special Studies. Cardiac catheterization revealed a pulmonary capillary pressure of $25 \mathrm{~mm}$. Hg. The pulmonary artery pressure was $35 \mathrm{~mm}$. $\mathrm{Hg}$; the pulmonary vascular resistance was not abnormal. The mitral valve area was calculated to be $2.5 \mathrm{~cm} .{ }^{2}$ (Gorlin and Gorlin, 1951). There was evidence of right ventricular failure and tricuspid regurgitation, but not of a left-to-right shunt. The resting cardiac output, determined by the Fick method, was $10 \cdot 31 . / \mathrm{min}$. (6.3 1./min./m. $\left.{ }^{2}\right)$. Additional laboratory tests revealed hæmatocrit value of 45; a 24-hour radioactive iodine uptake of 25 per cent, and normal renal and hepatic function tests.

Course. The patient continued to have progressive pulmonary congestion, ultimately developed chronic right heart failure and died two years after study. No necropsy was obtained.

Comment. Mild mitral stenosis was, in this case, much aggravated by a high cardiac output. If cardiac output had been normal $(6 \mathrm{l} . / \mathrm{min}$.), there would have been virtually no pulmonary hypertension (pulmonary capillary pressure $10-12 \mathrm{~mm}$. $\mathrm{Hg}$ ).

Case 7 (T. M.). The patient was a 27-year-old labourer who had been well throughout his life, and had had no cardiopulmonary symptoms, and had normal exercise tolerance. At the age of 3 a systolic murmur was heard. There was no history of scarlet fever or rheumatic fever. The family history was negative for heart disease. In 1946, when he was 15, right heart catheterization was performed.

Physical Examination. Blood pressure 125/60; pulse 76. The jugular venous pressure was normal and carotid pulsations were full, bounding, hyperactive, and bisferiens in quality. The point of maximal im- 
pulse was forceful and located $2 \mathrm{~cm}$. lateral to the mid clavicular line in the fourth intercostal space. At the left sternal border, a right ventricular heave was noted. P2 was louder than A2. There was a grade 4, short, high-pitched, systolic murmur at the left sternal border, loudest at the third intercostal space. A third heart sound was heard over the entire præcordium. The mitral first sound was normal. The remainder of the examination was normal. Incomplete right bundle-branch block and left ventricular hypertrophy (diastolic overloading of both ventricles) were seen on the electrocardiogram (Fig. 1). Chest

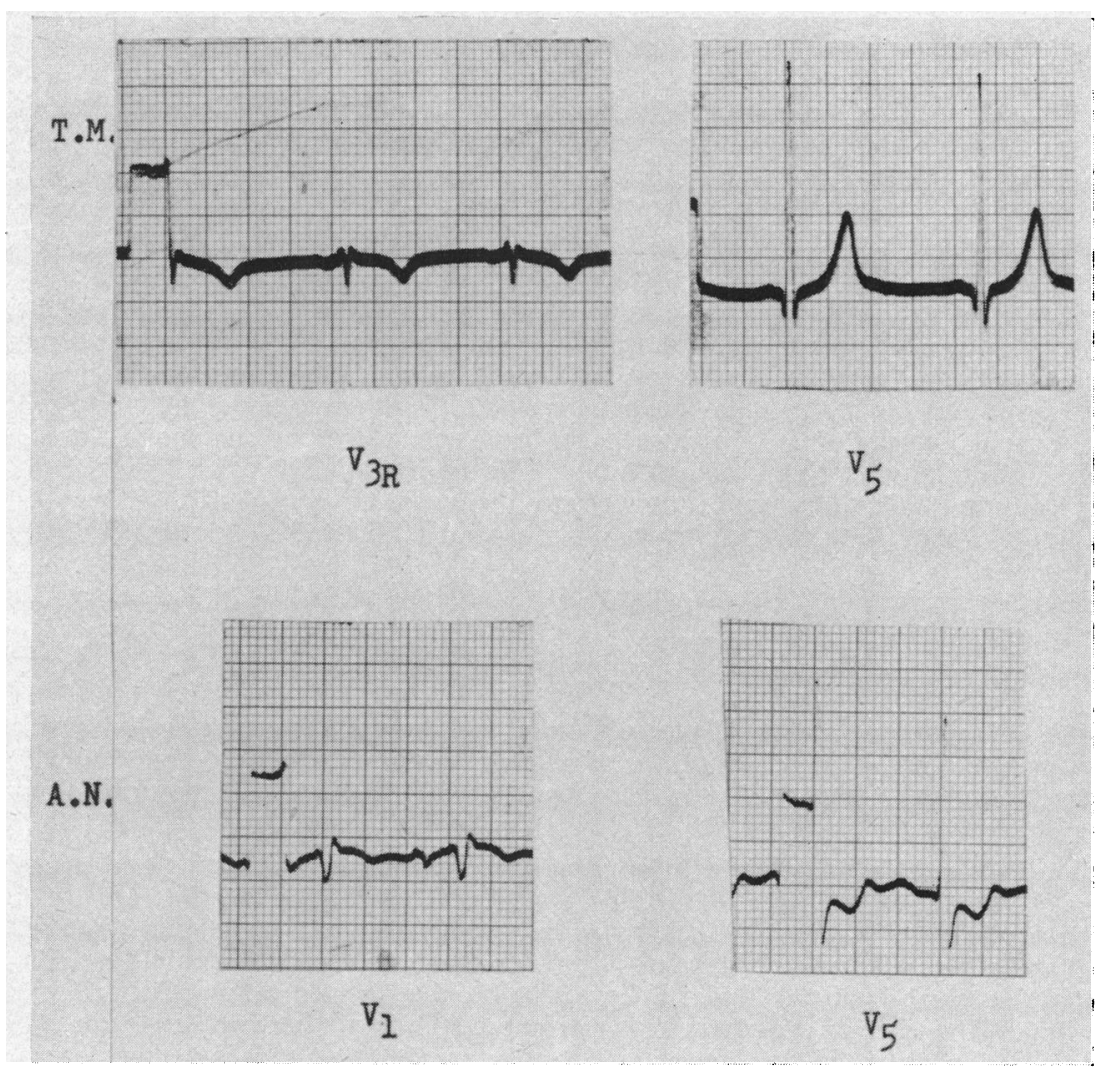

Fig. 1.-Cardiographic patterns of two patients are shown above. Note the $\mathrm{rSr}^{\prime}$ configuration in the right præcordial leads and the high $T$ waves in $V_{5}$ in T.M. A.N. was on digitalis which may have modified the pattern over the left ventricle.

film showed normal transverse diameter of the heart with left and right ventricular prominence and increase in the pulmonary arterial segment. The lung fields were engorged. The aortic arch was full. The radiologist considered the findings to be consistent with a ventricular septal defect.

Special Studies. During the cardiac catheterization performed at the age of 15 , cardiac output was $7 \cdot 21 . / \mathrm{min}$. (5.6 1./min./m. $\left.{ }^{2}\right)$. Right heart pressures were within normal limits with no evidence of left-toright shunt. The patient was re-admitted for study 12 years later at the age of 27 . The cold pressor test was positive, but the clinical laboratory studies were normal (see Case 1 for detailed list). Cardiac outputs at rest, during exercise, and five minutes after (Pritchard et al., 1958) were 5.7, 6.3, and 5.2 1./min./m.2 respectively. Blood pressure at rest was $124 / 55$ and rose to $146 / 80$ on exercise. The heart rate increased from 76 to 104 with exercise. Prolonged rest (light sleep) in a quiet room did not decrease the raised cardiac output.

Comment. This patient had a murmur present most of his life with known electrocardiographic and $\mathrm{X}$-ray abnormalities of 13 years' duration. In addition, he has had evidence of an increased cardiac output during this period. His electrocardiogram at the present time meets the criteria for diastolic overloading of both ventricles. 
Case $8(A . N$.$) . The patient was a 27$-year-old man complaining of fatigue. He had a vague illness as a child with "aches all over," but no definite history of acute rheumatic fever or scarlet fever. He had normal effort tolerance until 12 years before admission when he had become more breathless on severe exertion than his companions. Ten years before admission, he was told that his heart was found to be enlarged on X-ray and that he had a heart murmur. Eight years before admission he became easily fatigued on exertion and this has increased gradually to the present time. During the past two to four years, he had noted occasional premature beats and a non-productive cough. There was no family history of heart disease.

Physical Examination. Blood pressure 140/90; pulse 80; respirations 18 . The head was slightly increased in size and there was a spina bifida. Jugular venous pressure was normal. The carotid arteries were forceful and collapsing, but without a thrill. The heart was enlarged to the left and there was a slight right ventricular heave. The left ventricular impulse was forceful. P2 was accentuated. There was a grade 3 rough systolic murmur $4 \mathrm{~cm}$. to the left of the sternal border in the third intercostal space, radiating to the apex and to the base. The mitral first sound was decreased.' The liver was felt one to two finger breadths below the right costal margin. There was non-pitting, brawny œdema of both legs. No bruits were heard. The electrocardiogram revealed incomplete right bundle-branch block, left ventricular hypertrophy, and prominent $\mathbf{P}$ waves in leads II and III (Fig. 1). The X-ray of the skull was normal. That of the chest showed generalized cardiomegaly with prominence of the right and left ventricles. The left atrium was normal. The aortic knob and arch were within normal limits. The pulmonary artery was greatly enlarged and there were conspicuous pulmonary vascular markings.

Special Studies. Right heart catheterization was performed and showed pulmonary pressures to be normal except for a 5-mm. elevation of pulmonary capillary pressure on effort. The mixed arteriovenous oxygen difference was narrowed, but no evidence of a left-to-right shunt could be found. The Fick cardiac output was $7.01 . / \mathrm{min} . / \mathrm{m} .{ }^{2}$ with normal rate and blood pressure. These findings were confirmed on repeat catheterization three days later, and again three years later the cardiac output was found to be still raised at rest, on effort, and during sleep. The circulating blood volume was increased to $4.01 . / \mathrm{m} .{ }^{2}$ on two occasions, but all other laboratory studies gave normal results.

Comment. Our findings were persistently abnormal in this patient over a three-year period. The cardiac output did not change following two months of reserpine therapy $(0 \cdot 25 \mathrm{mg}$. daily).

\section{Clinical Findings}

Since all patients were referred to us, they had naturally been seen by another physician, usually as part of a college or employment physical examination, at which time a murmur had been heard. To this extent, our patients have been "pre-selected" and we are unwilling, therefore, to attribute any significance as yet to the fact that they were all men between 17 and 48 years of age.

They were generally free from subjective complaints. Only Case 6, with mitral stenosis aggravated by the high cardiac output state, and Case 8 , with incipient heart failure, had moderate exertional fatigue. The others were apparently normal subjects, so symptom-free as to resent somewhat the protracted and apparently unwarranted interest of the attending physician. The occupation varied widely from labourer to student. Four of the patients, by virtue of athletics or occupation, were considered to be in good physical condition at the time of observation. Anxiety, but not selfconcern, seemed prominent in at least six of the eight patients.

The patients were of varying, but average, body build and free of deformity except Case 8 who had a large cranium and Case 2 who had a moderate pectus excavatum. The blood pressure was often labile, occasionally with systolic hypertension and a wide pulse pressure. The cold pressor test was positive in five of the six patients tested. The pulse rate was usually normal. Skin colour and warmth were normal. There was no tendency to sweating and none had evidence of hæmangiomata. In over half of the patients, the carotid pulsations and left ventricular impulses were hyperactive on palpation, but in the others, there was no detectable increase in activity. In each case there was a murmur of varying intensity generally located between the pulmonary area and the mesocardium, and usually of a "flow" type, blowing in quality. No bruits could be detected over any organ or great vessel. No other physical characteristics of importance could be discerned.

The electrocardiogram was abnormal in all the patients, and in each there was evidence of right 
or left ventricular overloading. The electrocardiographic change characteristic of high blood flow, diastolic overloading (Sodi-Pallares and Calder, 1956), was seen in four patients (Fig. 1). By X-ray, the lung vessels were more prominent than normal in half of the patients and there was evidence of shouldering of the right ventricle or posterior rotation of the left ventricle in over half. On the other hand, the X-ray findings were unimpressive in some, but fluoroscopy did reveal increased activity of the cardiac borders.

\section{Physiological and Differential Diagnostic Studies}

All patients had a strikingly increased systemic cardiac output and decreased peripheral resistance at rest (Fig. 2). Except for a wide pulse pressure and increased stroke volume, no other abnormality could be discerned.

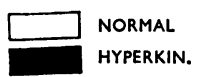<smiles>[14CH3][AlH2]</smiles>
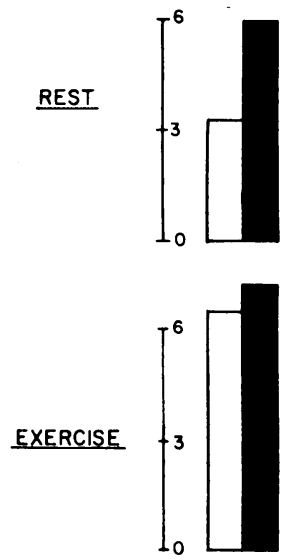
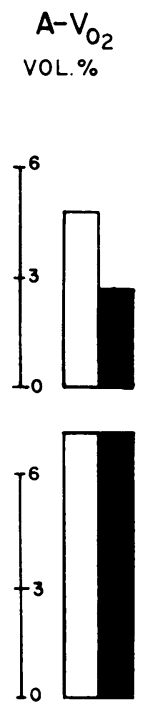
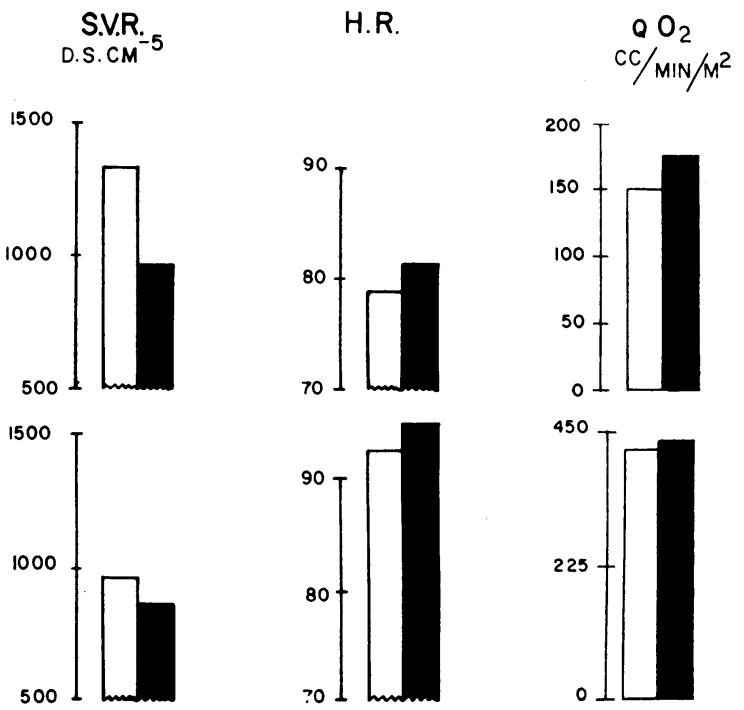

FIG. 2.-Comparison of average hæmodynamic values at rest and during effort between our controls and patients with hyperkinetic state. $\mathrm{CI}=$ cardiac index; $\mathrm{A}-\mathrm{V}_{\mathrm{O}_{2}}=$ arteriovenous oxygen difference; $\mathrm{SVR}=$ systemic vascular resistance (dyne sec. $\left.\mathrm{cm} .{ }^{-5}\right) ; \mathrm{HR}=$ heart rate; $\mathrm{Q} \mathrm{O}_{2}=$ oxygen consumption.

There was no clinical evidence of thyrotoxicosis, liver disease, pulmonary disease, Paget's disease, hereditary telangiectasia, anæmia, or renal disease. Pertinent laboratory tests served to exclude, as far as possible, these diagnoses. Cardiac catheterization revealed no evidence of leftto-right shunts and the uniformly high superior and inferior vena caval oxygen samples ruled out a single large vessel arteriovenous aneurysm.

Lack of subjective symptoms, good physical training in half the patients and normal exercise lactate and pyruvate values ruled out both vaso-regulatory asthenia (Holmgren et al., 1957) and neuro-circulatory asthenia (White et al., 1944). Good evidence against transient anxiety was obtained from sedation (Hickam et al., 1948) and sleeping studies, both of which generally failed to alter the high output state.

\section{DiAGNOSIS}

Method of Detection of Patients. It is our belief that these patients constitute a distinct clinical entity. What diagnostic criteria, then, may be of value in the recognition of this syndrome? 
Some clues are available from examination of our cases. One patient was initially seen for evaluation of mitral stenosis producing disabling pulmonary symptoms: the possible primary significance of the high cardiac output was appreciated only in retrospect when the patient was found to have a very mild mitral stenosis. The other seven were referred for assessment of a non-specific cardiac murmur. In only two of these was the diagnosis of idiopathic high cardiac output suspected clinically prior to full laboratory studies.

The first clue, therefore, in diagnosis will be the presence of a cardiac murmur, particularly when the murmur itself or the associated findings do not suggest a specific disease. Indeed, some patients with so-called functional murmurs may have a high cardiac output. Persistent overactivity of the heart and large arteries has been of importance, particularly when no obvious cause such as aortic regurgitation, hypertension, ventricular septal defect, or patent ductus arteriosus can be found. One of the commonest differential diagnoses on physical examination will, of course, be ventricular septal defect with high pulmonary blood flow, and, occasionally, cardiac catheterization may be necessary to rule this out. We have found the contour of indicator dilution curves helpful in this differential diagnosis. Another clue is labile blood pressure or persistently wide pulse pressure in the absence of hypertension or aortic regurgitation. Here, the effect of transient anxiety can usually be eliminated by a period of rest.

All of our patients showed some electrocardiographic change indicating ventricular hypertrophy, often of the high blood flow or diastolic overloading pattern. Therefore, high cardiac output must be considered in the patient with unexplained ventricular hypertrophy. Less striking, but of equal importance, were the X-ray changes. Pulmonary plethora or ventricular prominence without apparent cause may be diagnostic clues, particularly if coupled with overactivity of the cardiac silhouette as seen by fluoroscopy.

The diagnosis, then, is one of suspicion. The syndrome can mimic so many other states that it can undoubtedly be easily overlooked. When a firm diagnosis cannot be offered, and there is a murmur and also overactivity of the heart, the possibility of high cardiac output should be entertained.

\section{PATHOGENESIS}

The exact cause of the high output remains a mystery. Although it is not possible to rule out a diffuse arteriovenous anomaly, we believe that the disease is primarily a defect of central (neurohumoral) regulation of cardiac output. We have been impressed by the fact that our patients tended to be anxious, but we have no data to suggest a relation between chronic anxiety and a chronically hyperkinetic circulation. Some slight evidence against this is the known presence of murmurs since childhood in three patients. Stevenson et al. (1949) have suggested that patients with anxiety and easily provoked cardio-acceleration are particularly prone to the ultimate development of heart disease. No such conclusions can yet be inferred from our studies.

\section{Prognosis}

It is much too early to prognosticate. The syndrome obviously has a long course. Murmurs had been known to exist in some patients for 20 to 30 years prior to observation and study. High flow states, for example, patent ductus arteriosus, ventricular septal defect, and aortic regurgitation, take years to precipitate heart failure in otherwise normal hearts. Therefore, it is not surprising that thus far in our group, only two subjects seem to have had clinical difficulty: Case 6 had severe clinical symptoms because a high cardiac output aggravated his mitral stenosis; and Case 8 with a murmur of 10 years' known duration, now has cardiac enlargement and early left ventricular failure at the age of 27 . All the patients, regardless of symptoms, had evidence of ventricular hypertrophy; it seems possible at least that dilatation and failure will ultimately occur in all.

Therapy. Administration of reserpine has been instituted in the five patients not lost to followup. In Cases 1 and 5, after one month of therapy, the cardiac output, stroke volume, and blood 
pressure have returned to normal at rest, with normal responses to effort. Such a salutary response was not seen in Case 8. Follow-up studies on the other two patients are not yet available.

\section{SUMMARY}

Eight patients are presented who had in common, a systolic murmur, cardiac hypertrophy, a raised cardiac output, and low peripheral resistance. One patient ultimately died of mitral stenosis of mild degree, but severely intensified by high cardiac output, and one was in early left heart failure. No known cause of the high output state has been defined thus far. These patients may constitute a new clinical entity.

Addendum. Since writing this paper three further patients with this syndrome have been identified. One was a woman and all were between 18 and 20 years old.

The authors are indebted to Dr. Lewis Dexter who generously furnished information on two patients, Drs. Albert Renold and Dale Friend through whose laboratory assistance we were able to obtain catechol amine levels and lactate-pyruvate studies, and to Drs. John D. Turner and Eduardo Salazar who performed the observations during sleep which are reported herein. Cardiac catheterization in Cases 6 and 7 was carried out in the laboratory of Dr. Lewis Dexter. The technical and secretarial aid of Miss Elin Alexanderson, Mrs. Elizabeth Hughes, and Miss Eunice Ward is gratefully acknowledged. Serpasil was kindly supplied by CIBA Pharmaceutical Products Inc.

\section{REFERENCES}

Brock, R. (1957). Guy's Hosp. Rep., 106, 221.

Clark, W. S., and Bauer, W. (1948). Ann. rheum. Dis., 7, 39.

Gorlin, R., and Gorlin, S. G. (1951). Amer. Heart J., 41, 1.

Hickam, J. B., Cargill, W. H., and Golden, A. (1948). J. clin. Invest., 27, 290.

Holmgren, A., Jonsson, B., Levander, M., Linderholm, H., Sjostrand, T., and Strom, G. (1957). Acta med. Scand., 158, 414 .

Mattingly, T. W., and Sjoerdsma, A. (1956). Mod. Conc. Cardiov. Dis., 25, 337.

McKusick, V. (1955). Circulation, 11, 321.

Pritchard, W. H., MacIntyre, W. J., and Moir, T. W. (1958). Circulation, 18, 1147.

Silber, E. N. (1958). Ann. intern Med., 48, 228.

Sodi-Pallares, D., and Calder, R. M. (1956). New Bases of Electrocardiography. Translated from the 3rd Spanish edition, C.V. Mosby Co., St. Louis.

Stevenson, I. P., Duncan, C. H., and Wolff, G. H. (1949). J. clin. Invest., 28, 1534.

Thomas, W. A., Randall, R. V., Bland, E. F., and Castleman, B. (1954). New Eng. J. Med., 251, 327.

White, P. D., Cobb, S., Chapman, W. P., Cohen, M. E., and Badal, D. W. (1944). Trans. Ass. Amer. Phys., 58, 129. 